\title{
To Infinity and Beyond - Are Innovation Contests at Austrian Technical Colleges the Right Tool to Stimulate the Creative and Technical Potential of the Country?
}

\author{
http://dx.doi.org/10.3991/ijep.v3i1.2307 \\ Dr. Axel Zafoschnig \\ VET Inspectorate, Board of Education Kärnten, Klagenfurt, Austria
}

\begin{abstract}
Nowadays, creativity as it is applied for finding new technologies and making new inventions, is characterised by new unorthodox aspects of and approaches to problem solving. At the same time, innovation uses new scientific, technical and cultural elements to sustainably change the social structure of society. However, creative and innovative ideas are not affluent or ever-lasting resources. They need to be stimulated, elicited and put into realisation. This has to be done through expensive research and development campaigns, but may also be achieved at a lower level, namely, for example, at Austrian Technical Colleges. There, students are often encouraged to submit their diploma thesis projects in national and regional competitions and have recently proved to be very successful.
\end{abstract}

Index Terms-Austria, contests, creativity, diploma thesis, EQF, innovation, school, technical colleges, VET.

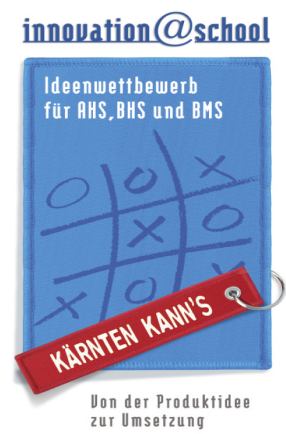

\section{CREATIVITY AND INNOVATION AT SCHOOL}

The young people of today like to think, to explore and to take risks. These three elements - together with trial and error learning - already make up some main components of the concept of being creative. However, creative ideas and innovative processes can only happen in a safe and comforting environment. The crucial question in this respect now is, if creativity and innovation can happen in a school to such an extent that they may be a benefit for the prosperity and the economic growth of a country.

Before we can look at this question in detail, we will first have to analyse and define what creativity and innovation mean and how they are interrelated. From a pedagogical point of view, didactic experts and educators tend to think that creativity at an early age is expressed best through music, grammar or the visual arts [1]. If, you are, however, a teacher at an Austrian VET college, the concept according to which creativity is only artistic, cannot be maintained.

In a context of vocational education and training, creativity has a wider and more integrative meaning, it means being open to chance and opportunity, as well as to generating what is new and original. This is where innovation comes into the game, because through creative thinking and acting new technologies, products and methods of operation can be discovered. But knowing these facts can lead to erroneously thinking that we should distinguish strictly between creativity and innovation. In an organisational background, for instance, creativity is often seen as the generation of new ideas, whereas innovation is regarded as the translation of such an idea into a new product, service, or method of production. That is why we often find the creative people in one department and the innovative ones in another.

Two further such definitions that distinguish between creativity and innovation are for example Lawrence B. Mohr`s [2] concept, according to which creativity implies "bringing something new into being; whereas innovation implies bringing something new into us", or the definition by Rosabeth Kanter [3], who says that "innovation is the generation, acceptance, and implementation of new ideas, processes, products or services". So the art of innovation seems to be characterised simply by the success that an idea has achieved in the end.

In this connection, some management experts also claim that modern organisations may need both, creative an innovative people, amongst their human resources. Peter F. Drucker, one of the pioneers of modern management, suggests a few straight-forward but obviously efficient strategies to become innovative. Firstly, he states that all successful innovations have begun on a small scale and have been adapted for larger markets in the course of time. Secondly, innovation needs a concept, a plan, a strategy, but most of all it needs understanding, empathy and attention from the decision-makers. Thirdly, most innovations that have made a technological or economic break-through are disarmingly simple [4]. With these prerequisites in mind, technological innovations that change the conditions in the marketplace can be made more easily. Having now listened to Drucker`s analysis, it seems that being open for new ideas and helping them to surface 
already means half the success. Innovations are, so to speak, the turbo-chargers for high-performance motors that help us drive into the future.

To translate creative talents into results in educational institutions, we need, however, innovative learning environments [5] that empower and encourage our students to be creative and to take risks. But for that, additional incentive factors have to be considered. This is easier said than done. Even in a world of professional innovators, who work in think-tanks and incubators, innovative ideas remain a scarcity. Through the modern electronic means of communication every innovation has become a victim of what might be called the accelerated, globalised innovation process. Twenty years ago it took researchers and scientists approximately 10 months to get their innovation to interested readers and target groups through scientific journals. Nowadays, this process does not take longer than 10 seconds, which means that innovative ideas may be received, reflected upon and further developed within considerably shorter time (Instead of thinking in years, organisations have switched over to thinking in weeks : planning the next 520 weeks sounds less terrifying than planning the next 10 years !). Innovation has thus become a world-wide and readily available commodity - if there were enough people to have such sparkling and revolutionary ideas. With the vast demographic background of 7 billion people, creativity and innovation cannot only be left to random developments and professional thinkers about the future.

The adult world alone is by no means a guarantee for creative and innovative success stories. We need to motivate the younger generations, children at nurseries and school, students at colleges and universities, to think about the future, to deal with the unexpected, and to find solutions as well as answers to emerging challenges, however science-fiction-like they might look. If you do not encourage creativity in children from an early age on, the process of preparing them for an unpredictable and unknowable future is not going to be successful. Thus, we have to build creative schools in which the two processes "creative teaching" and "teaching for creativity" [6] are getting enough room.

\section{IDEA CONTESTS AND INNOVATION CHALLENGES}

One such way towards achieving creativity and innovation at the same time is to motivate young people to take part in so called creativity and innovation contests on a regional or even national level, like the HTL do it in Austria, where competence-based curricula and occupational standards have been introduced in the new curriculum generation [7]. In the preparation phase for such contests, the students are mentored by teachers and cooperation partners from the industry alike and learn how to perform successfully and with a feeling for the division of labour in teams.

But the path to such participation is long and stony, how it can be achieved shall also be investigated in this paper. In this respect, one thing is certain: if we expect our younger generation to set creative actions and to innovate society, we have the responsibility to enable them and to empower them to be creative and innovative. This means we must help them to explore ideas, we must promote and reward imagination and originality. At school, such an ambitious objective can only be achieved trough a dy- namic concept to school development and through motivated teachers who help the students to realise their creative and innovative potential. In this respect, Austria has already taken some practical steps into the right direction at the VET colleges.

With the formula:

\section{Creativity + Innovative Thinking $x$ Team spirit $=$ Project idea (Realisation)}

which also serves as the slogan for the only recently implemented innovation contest innovation@school [8], the main ideas of the campaign on a regional level, in Carinthia, have been disseminated. Within the project, the youngsters can first share ideas and then take it from there to develop their findings further. Trial and error learning plays an important role at the beginning of the process and, like with Thomas A. Edison, it might first lead to failure, but finally to innovation. Key-words that certainly characterise every innovation process in this respect are: the so-called hockey-stick development, or the decisive tipping points, the drivers, and the break-through technology that brings about genuine success.

In Carinthia, Austria's southernmost region that borders Italy and Slovenia, young people have always been curious and open-minded, culturally and technologically interested and, above all, keen on creative and innovative ideas in the sense that "innovation is the ability to see change as an opportunity, not as a threat" [9]. Consequently, the education authorities together with the commercial and industrial enterprises have decided to launch a number innovation contests for Technical Colleges which has now been up and running for the past 6 years. In the contest, the whole process from generating an idea to its implementation is important.

The main idea behind the whole competition is that students must register as a team which intends to carry out a cooperation project with a partner that is either an industrial enterprise or a smaller technical company. When the team submits the idea, this must happen with the help of a form that requires the following information:

- Description of a project idea

- Explanation of the innovative character of the project

- Expected benefits of the project for the project partner

- Expected benefits for the teachers involved

- Expected benefits for the students (with reference to the subjects of the curriculum)

- Expected benefits for the school

- Summary

As far as the procedure and the strategy for the realization of those projects are concerned, the student teams are requested to cooperate fully with the teachers and the industrial partners. In full detail this means that the abovementioned description of the project idea should consist of at least 200 words, that it is accompanied by a graphic illustration of the product (sketch, technical drawing), and that all the materials and parts needed shall also be listed. In addition, the tasks which are assigned to each team member shall explicitly be laid out in the description. The main focus, how ever, lies on the innovation content of the product that is to be developed in cooperation between the students and the company. In this connection the jury will 
have to decide how well the students have outlined and later on recorded the degree of implementation and fulfilment of the specifications for each particular project. This means, they have to prove the practical realization of theoretical project with the help of a model or a prototype. Finally, the special benefits of the product shall be elaborated and the characteristic features of the product shall be described. If all the requirements have been fulfilled, the project documentation may be submitted to the jury and the technical and economic experts than decide which ten products go on into the final. In that final which usually takes place at the beginning of June the winner is than chosen and the price money is awarded.

In this year's contest innovation at school sixty-two projects were submitted by more than ten schools. The greatest part of the project submissions came in the sector information and communication technology with thirtyone projects, the two next bigger groups were ideas related to industry and trade, as well as to energy, production and the environment-both groups had eight projects each. In the fourth, fifth and sixth categories there were five projects each, whereby these project categories were called: tourism, health and social affairs, and art and culture. Out of these sixty-two projects twenty-six came from HTL Klagenfurt Mössingerstraße, fifteen from HTL Klagenfurt Lastenstraße, six from HTL Wolfsberg, four from HTL Ferlach, four from Carinthian tourism collage, three HTL Villach, and one each from HAK Völkermarkt, BORG Wolfsberg and BG Ingeborg-Bachmann. With regard to cooperation partners in the industry and in trade, twenty-nine companies were involved which come from the sectors of industry, trade, commerce, education, as well as from several NGOs (social affairs, health, tourism, sport).

The high number of projects that were submitted (and continue to be submitted in this year's competition) clearly shows that young people who are educated and trained within a prospering VET sector like to be challenged. They are keen on presenting their creative and innovative ideas to their peers within a contest that serves as a valid kind of benchmarking, and on satisfying both, their individual curiosity as well as their team spirit, when it comes to tackling research and development. The welldeserved pride in the participants' faces is another asset for the personal and professional development of the young innovators and the photos from the awarding ceremony also show that politicians and dignatories from different sectors, among them industry and education use the opportunity to present themselves to the general public within the future generation of innovative scientists and engineers.

In co-operation with their industrial partner, the company ASTAM, the Wolfsberg Technical College team have designed a lifting device for noise-protection boards that is based on the simple idea of a combination between the Archimedean spiral and the Eccentric clamp. The company Velox produces noise-protection boards which are used to set up noise barriers for motorways. During assembly, the boards have to be transported from their storage place to the supporting structure within which they are fastened. So far, this transport has been carried out manually, although the boards weigh more than $50 \mathrm{~kg}$.

This is where the students' innovation came in: a crane with a swivel-arm was built and a new fastening device was installed, since the boards could not be lifted and
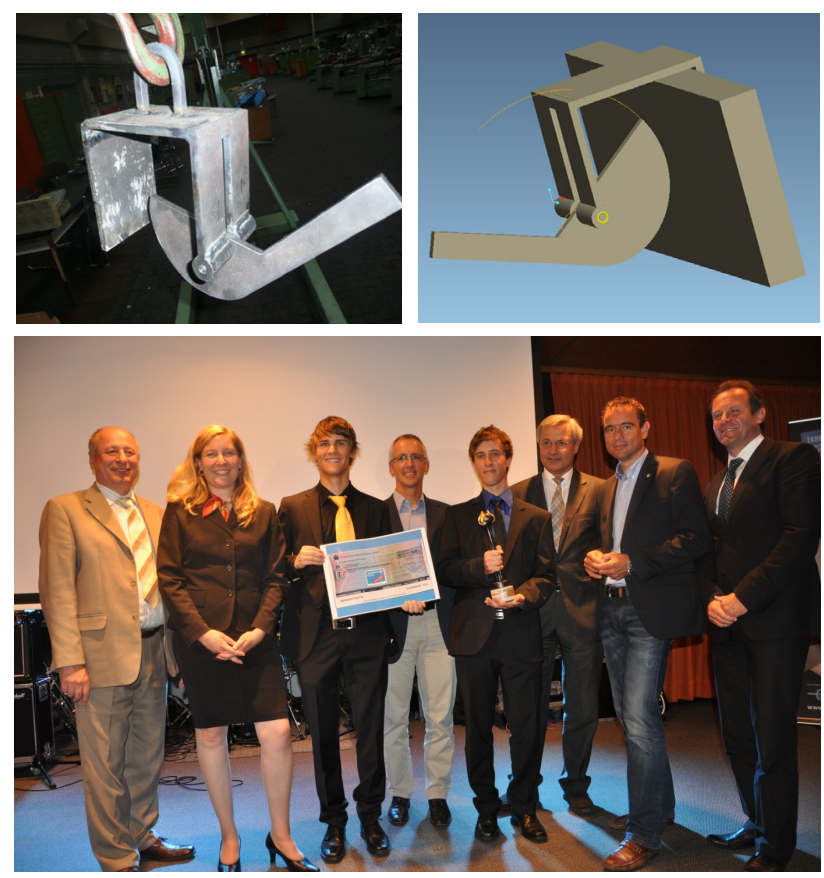

Figure 1. innovation@school 2010/2011: The winning team of HTL Wolfsberg with their idea of a lifting device for noise-protection boards

moved with ropes as in conventional cranes. The ropes would have made work more difficult and could not have been used in assembly. The main problem was that a device had to be found that could cope with the different board thicknesses and would also support, not disturb, the assembly process. The students tried a vacuum lifter first, but failed, because the VELOX boards are permeable to air. So, they finally combined two physical principles, that of the eccentric clamp and that of the Archimedean spiral, which in the end proved very successful. It is a special feature of the Archimedean spiral that the point of action of the force and thus also the forces always remain the same irrespective of the board thickness.

The whole device was then designed and programmed with the help of the 3D-CAD software PRO-Engineer and the prototype was manufactured with a CNC plasma cutting machine. With this innovative device, the productivity and the efficiency of the production process could be increased and only one man is now necessary for transport and assembly.

In 2010, HTL Mössingerstraße won the contest with their project M.M.S. (Moisture Measuring System) which they carried out together with their co-operation partner, the brick factory Ziegelwerk Brenner in Wolfsberg. The objective was to achieve a continual measuring process during the drying of the bricks in the dry room. The students managed to solve the problem by installing a network of sensors that provided the relevant data, like brick moisture and temperature, so that exact measuring became possible. Previously, the drying process had just been checked by weighing a brick and by destroying it. With the help of the measuring system, energy can be saved and emissions were reduced. In addition, the quality of the bricks could be improved and the company was particularly happy with the efficient solution that the project team from the Technical College had come up with.

Together with the Maschinenfabrik Stingl GmbH, the students designed a plant that sorts round timber of smaller dimensions (up to $30 \mathrm{~cm}$ ), collects the pieces and 

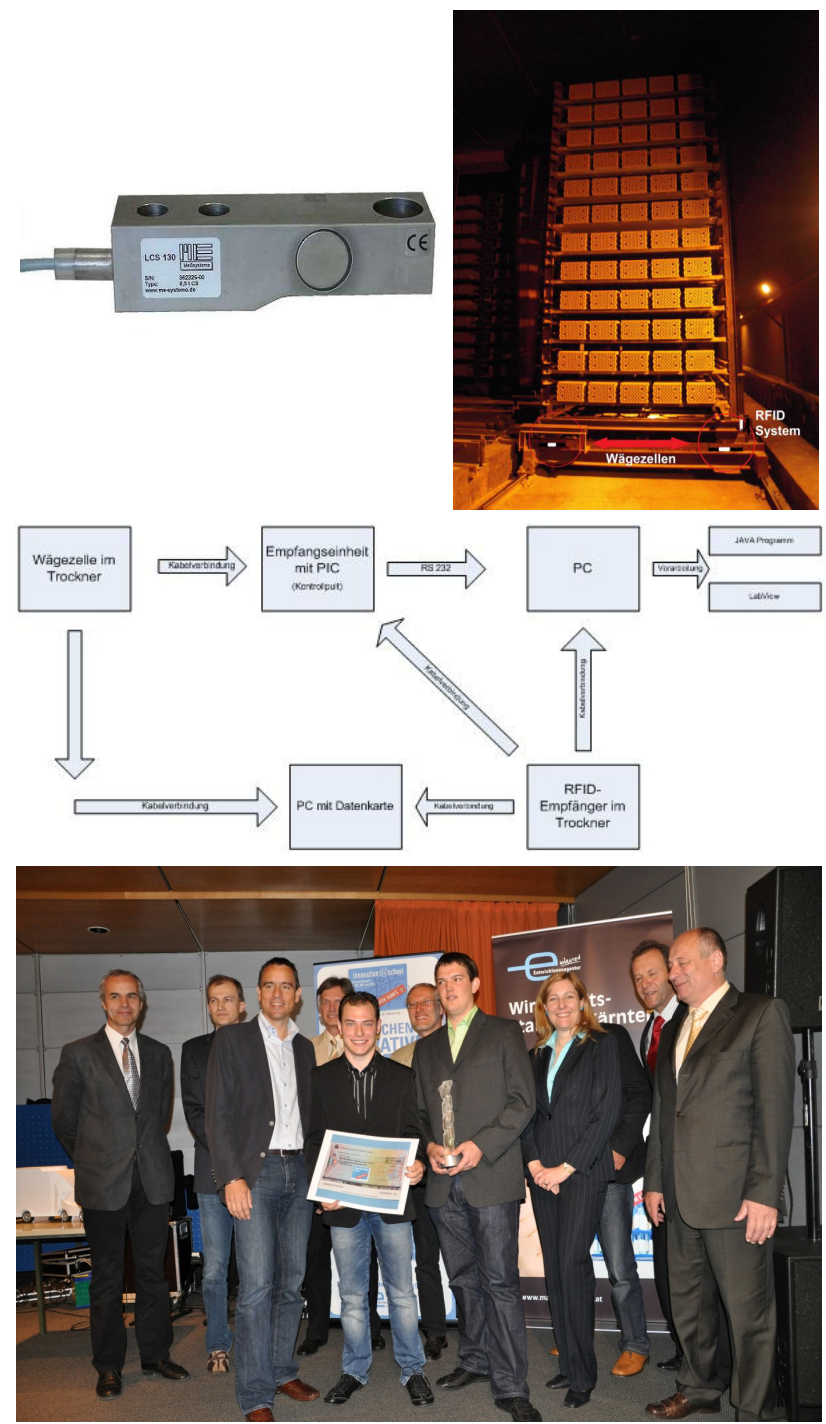

Figure 2. innovation@school 2009/2010: The winning HTL Mössingerstrasse team with their brick moisture measuring system

processes them into boards and squared lumber. The modular principle applied here helped the company to offer an all-in-one machining centre for small and medium sized enterprises.

\section{INNOVATIVE YOUNGSTERS AND INNOVATION MARKETPLACES}

According to Walt Disney's slogan "I believe in being an innovator", the Austrian Ministry of Education has launched a number of additional and versatile contests and competitions for students at upper secondary vocational technical colleges, because of the strong belief that such events stimulate the creative and technical potential of the youngsters. One such innovation contest on a national level is "Jugend innovativ" (innovative youth), a school contest for "intelligent heads", in which interested student teams can submit innovative projects in the fields of Business, Design, Engineering, Science and Climate Protection.

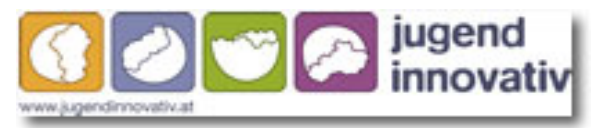

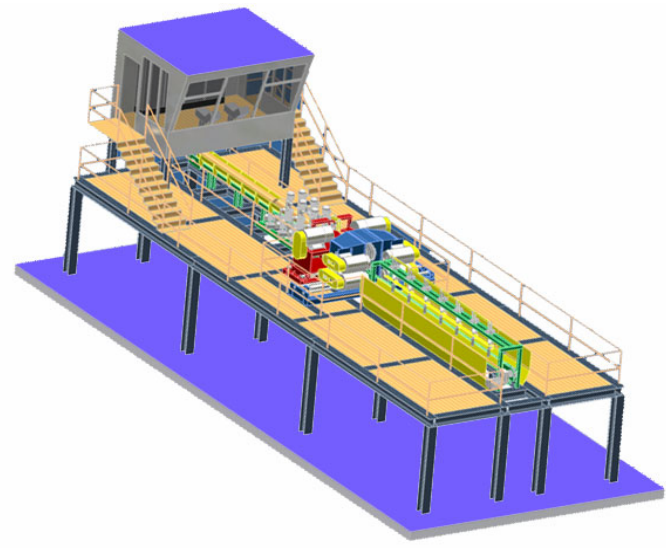

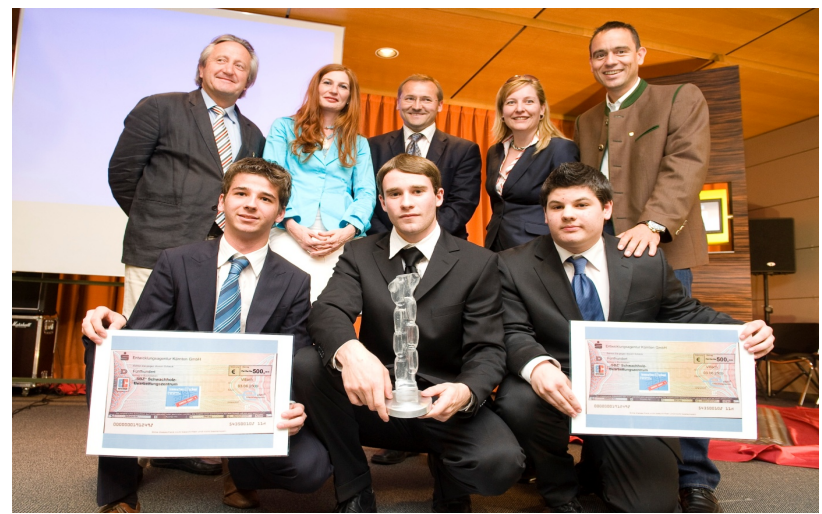

Figure 3. innovation@school 2008/2009The winning HTL Lastenstraße team with their small-wood machining centre

Within this year's competition there is also a category called idea.goes.app, within which innovative, practically applicable and smart Apps and App-concepts are being looked for. The truly innovative element of this contest is that Austria's students can prove excellently that innovation is certainly not only a grown-up affair.

By presenting their brilliant and ingenious ideas to a greater public, the young people can show that a high creative and innovative potential is innate to them and that this potential can be well activated with the expert help of the various schools and teachers. An extra incentive to participate in the contest is the fact that the prizes are very attractive because the winning teams can attend international trade fairs, exhibitions, other contests or innovation workshops.

Another example of a successful youth competition is the "u19 Create Your World" contest within the Prix Ars Electronica in Linz, Upper Austria. There, children and youngsters alike may take part in what is Austria's largest computer competition which since 1998 has been serving as an interface between the creative spirit that young people represent on the one hand and the technological and social challenges of the future on the other hand. Internet applications, websites, graphics, computer animations, sounds and self-programmed software are only some areas in which the under-19s show their creativity, their imagination as well as their competence in coping with the new media and the new technologies. This year's winner came from the HTL Leonding, they won the "Golden Nica".

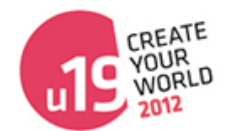


The transfer effect of the results generated as a consequence of taking part in a competition is extremely high for the students, especially with regard to the diploma theses they have to write, but also in connection with prospective jobs they may find in various technical fields where young expertise may be a scarcity. In Austria, the students at the Technical Colleges must all submit a diploma project which they complete in cooperation or on behalf of an industrial or commercial enterprise. To specify this, let us look at the following example: The chipproducer Infineon in Villach, Carinthia, is looking for a better temperature control system in one of their server rooms. This is not a very important problem for the company, it is not high up on their priority list. The students who get the assignment to look at a possible inexpensive way of solving that may take every time and effort to come up with a feasible solution. On the one hand, outside their classes, on the other hand inside the school laboratories and with the support and advice of the teachers, a win-win situation might arise from the task. The students can graduate with an excellent technical performance in their final exam, they may also submit their results within one of the leading innovation contests in the country, and the company gets a problem solved for whose solution they would not have had the personnel resources, because they would all be bound in other activities.

This example clearly shows that such problem-solving processes that are carried out on site, but are also presented in competitions, can benefit the young people as well as the already established enterprises, and thus the economy of the whole nation. Just for completeness, some other successful Austrian innovation contests like "Sparkling Science", "Invent a Chip", or the 3D-CAD competition "Let's become imagineers!" [10] should also be mentioned in this connection, since they thoroughly confirm the theory that best-practice results that have been awarded in such innovation contests really stimulate the creative and technical, but also the cultural potential of the country and shall thus continue to be organised by the education authorities and the industry.

\section{REFERENCES}

[1] Cochraine P. / Cockett M., "Building a Creative School”, Trentham Books, Stoke on Trent, 2007, p. 2

[2] Lawrence B. Mohr, "Determinants of Innovation in Organizations”, New York, 1969, pp.12 -25

[3] Rosabeth Kanter “The Change Masters”, New York, 1963, p. 20

[4] Peter F. Drucker, "Entrepreneurial strategies", California Management Review 27, no. 2 (Winter 1985): pp.9-25 http://dx.doi.org/10.2307/41165126

[5] Schrittesser, Frauendorfer, Krainz-Dürr (eds.), „Innovative learning environments“, Facultas Verlag, Wien, 2012, p.10

[6] Cochraine/Cockett, P., M., "Building a creative school", Trentham Books, Stoke on Tent, 2007, p. 9

[7] Zafoschnig A., Pachatz W., "Education standards and competence-oriented curricula - the Austrian Technical Colleges pursue a new way into the future", in "Forming International Engineers for the Information Society" (Talk), Santos, Brazil, 2011

[8] http://www.innovation-school.info (for details)

[9] Levitt T., “The Marketing Imagination”, N.Y., 1983, pp.

[10] http://www.bmukk.gv.at (for more innovation contests)

\section{AUTHOR}

Axel Zafoschnig is Chief Inspector of VET Colleges in Carinthia, Austria, IGIP Board Member, Klagenfurt, Austria, axel.zafoschnig@lsr-ktn.gv.at

This article is an extended and modified version of a paper presented at the IGIP2012 conference, held 26 - 28 September 2012, in Villach, Austria. Received15 October 2012. Published as resubmitted by the author 18 December 2012. 